\title{
Comparison of Clinical Characteristics and Effects of Modified Jaw Thrust Maneuver During Drug-Induced Sleep Endoscopy (DISE) between Positional and Non-Positional Obstructive Sleep Apnea Patients
}

\author{
Ji Seung Moon, $\mathrm{MD}^{1}$, Soo Kweon Koo, $\mathrm{MD}$, $\mathrm{PhD}^{1}$, Young Joong Kim, $\mathrm{MD}^{1}$, Sang Hoon Lee, $\mathrm{MD}^{1}$, \\ Ho Byoung Lee, $\mathrm{MD}^{1}$, Geun Hyung Park, $\mathrm{MD}^{1}$ and Sang Jun Lee ${ }^{2}$ \\ ${ }^{1}$ Department of Otorhinolaryngology, Busan Saint Mary's Hospital, Busan; and \\ ${ }^{2}$ Department of Otorhinolaryngology, Sleep laboratory, Busan Saint Mary's Hospital, Busan, Korea
}

\begin{abstract}
- ABSTRACT -
Background and Objectives : Positional OSAS is characterized by an apnea-hypopnea index (AHI) score $>5$, which, while sleeping in the supine position, is double that in non-supine position. This study was performed to compare the clinical characteristics of positional OSAS and non-positional OSAS patients, and the effects of the modified jaw thrust maneuver during drug-induced sleep endoscopy (DISE) between positional OSAS and non-positional OSAS patients. Materials and Methods : 68 positional OSAS patients and 19 non-positional OSAS patients were included. They all underwent full-night polysomnography and DISE. The modified jaw thrust maneuver was introduced during DISE. Airway structural changes induced by the modified jaw thrust maneuver were evaluated and documented. Results : There were no statistically significant differences in Friedman stage or tonsil grade, body mass index, Epworth sleepiness scale (ESS) score, blood pressure, AHI, or obstructive pattern between the positional and non-positional OSAS patients. However, mean arterial oxygen saturation $(\mathrm{SaO} 2)$, lowest $\mathrm{SaO} 2$, and total arousal index values were more severe in the non-positional OSAS patients. After introduction of the modified jaw thrust maneuver, retrolingual level obstruction showed a tendency toward a higher rate of airway opening in positional OSAS patients than in non-positional OSAS patients. Conclusions : The effects of a mandibular advancement device (MAD) can be estimated by carrying out a modified jaw thrust maneuver during DISE. The tendency toward a higher rate of airway opening in positional OSAS patients than non-positional OSAS patients in retrolingual level obstruction after jaw thrust maneuver introduced during DISE may be clinically important for MAD. (J Clinical Otolaryngol 2018;29:190-197)
\end{abstract}

KEY WORDS : Sleep apnea syndromes · Mandibular advancement device · Drug-induced sleep endoscopy.

\section{Introduction}

Obstructive sleep apnea syndrome (OSAS) is a common disorder characterized by recurrent episodes of

논문접수일 : 2018년 9월 19일

논문수정일 : 2018년 10월 25일

심사완료일 : 2018년 11월 27일

교신저자 : 구수권, 48575 부산광역시 남구 용호로232번길

25-14 부산성모병원 이비인후과

전화 : (051) 933-7214·전송 : (051) 956-1956

E-mail:koosookweon@naver.com breathing cessation due to upper airway collapse during sleep. Common symptoms of OSAS include unexplained daytime sleepiness, restless sleep, and loud snoring. It occurs when the throat muscles intermittently relax and block the airway during sleep. The severity of OSAS varies and is determined by multiple factors, including age, sex, body mass index (BMI), sleep posture, etc. Positional OSAS is a phenotype of OSAS in which sleep apneas come about largely during sleep in the supine position. ${ }^{1)}$ In 1984 , Cartwright $^{2}$ defined positional OSAS patients as those in whom the apnea-hypopnea index (AHI) was 
at least twice as high in the supine position than in the lateral position. Although prevalence rates vary depending on the criteria defining positional OSAS, positional OSAS accounts for a considerable proportion of the OSAS population, ranging from $50 \%$ to $60 \%$ of OSAS patients who present to sleep clinics. ${ }^{3,4)}$ Various surgical and non-surgical options are in use for the treatment of snoring and sleep apnea. Non-surgical methods include weight control, lifestyle changes, continuous positive pressure respiration, and use of intraoral devices, such as mandibular advancement devices (MAD). It is very meaningful to predict treatment outcomes, and a number of studies on various therapeutic predictors, such as physical measurements and polysomnography (PSG), have been carried out.

Positional therapy, such as avoidance of the supine posture during sleep, and use of MAD appears to be adequate in positional patients. ${ }^{5)}$ Yoshida et al. ${ }^{6}$ reported that the effectiveness of MAD therapy is greatly influenced by sleep posture.

Previous studies regarding treatment outcomes with MAD focused on changes in the overall severity of OSAS and did not examine defined subgroups of OSAS patients. Dynamic tests which can directly assess anatomical changes are very important in OSAS patients, and studies of dynamic pharyngeal airway collapsibility must be carried out to identify anatomical factors that contribution most to defining positional and non-positional OSAS. The jaw thrust maneuver is known to be effective for clearing the airway. ${ }^{7} \mathrm{~A}$ modified jaw thrust maneuver conducted under druginduced sleep endoscopy (DISE) allowed us to indirectly evaluate the degree of upper airway extension in patients with sleep apnea. Thus, we hypothesized that the treatment outcome of MAD according to subgroup could be anticipated by making observations of the anatomical changes of the upper airway with the modified jaw thrust maneuver under DISE according to OSAS subgroup.

This study was performed to compare the clinical characteristics of positional OSAS and non-positional OSAS patients, and the effects of the modified jaw thrust maneuver during DISE between positional OSAS and non-positional OSAS patients.

\section{Materials and Methods}

Before DISE, all patients received a exhaustive ear, nose, and throat (ENT) checkup. Their Friedman stage and tonsil grade were recorded. All patients underwent full-night PSG (WEE-1000K; Nihon Kohden, Tokyo, Japan). The research protocol was reviewed and approved by our institutional review board (IRB approval number BSM 2018-01).

\section{Materials}

We retrospectively evaluated 87 patients (mean age, 42.1 years ; range : $18-73$ years) diagnosed with OSAS in our hospital (defined as AHI score >5) from 2015 to 2017. We ruled out patients with obvious retrognathia or mandibular dysplasia, and those who had undergone prior surgery of the soft palate or tongue. To exclude any gender bias, female patients were also ruled out.

The study population was divided into positional patients with supine AHI score at least twice as high as the non-supine AHI score, and non-positional patients with a supine AHI score less than double the non-supine AHI score. Of the 87 subjects, 68 patients were included in positional OSAS and 19 patients were included in non-positional OSAS. There were no significant differences in age, BMI, mean Epworth sleepiness scale (ESS) score, or blood pressure (BP) between the two groups (Table 1).

\section{Drug induced sleep endoscopy}

In all cases, DISE procedures were carried out by ENT surgeons in a dim and quiet operating room, with each patient in the supine position. Sleep was induced by intravenous administration of midazolam and careful respiratory monitoring was followed. The anesthesiologist titrated the drug slowly to $0.07 \mathrm{mg} / \mathrm{kg}$ per patient ; boluses of 1-2.5 mg were given to a maximum of $7.5 \mathrm{mg}$ per patient using a target-controlled 
infusion system. An extra bolus was administered to the patients who were anxious. After the patient was deeply asleep (sufficiently to snore, show obstructions, and respond sluggishly to a light glabella or loud auditory stimulus : Ramsay's level of sedation scale score of $5^{8)}$ ), a flexible video laryngoscope of $4 \mathrm{~mm}$

Table 1. Demographic characteristics of the patients

\begin{tabular}{|c|c|c|c|}
\hline & Positional & Non-positional & p-value \\
\hline Number of patients & 68 & 19 & \\
\hline Mean age (mean $\pm S D$, years) & $42.5 \pm 12.8$ & $40.5 \pm 13.7$ & 0.730 \\
\hline $\mathrm{BMI}\left(\mathrm{mean} \pm \mathrm{SD}, \mathrm{kg} / \mathrm{m}^{2}\right)$ & $26.4 \pm 3.2$ & $27.0 \pm 4.0$ & 0.704 \\
\hline ESS score (mean \pm SD) & $9.1 \pm 5.0$ & $9.2 \pm 4.0$ & 0.786 \\
\hline $\mathrm{BP}($ mean $\pm \mathrm{SD}, \mathrm{mmHg}$, systolic $)$ & $127.6 \pm 16.8$ & $127.8 \pm 13.5$ & 0.798 \\
\hline $\mathrm{BP}($ mean $\pm \mathrm{SD}, \mathrm{mmHg}$, diastolic) & $79.6 \pm 11.1$ & $79.7 \pm 9.0$ & 0.819 \\
\hline
\end{tabular}

Statistics, Mann-Whitney U-test ; Statistical significance, $\mathrm{p}<0.05$. SD : standard deviation, BMI : body mass index, ESS Score : Epworth sleepiness scale score, BP : blood pressure
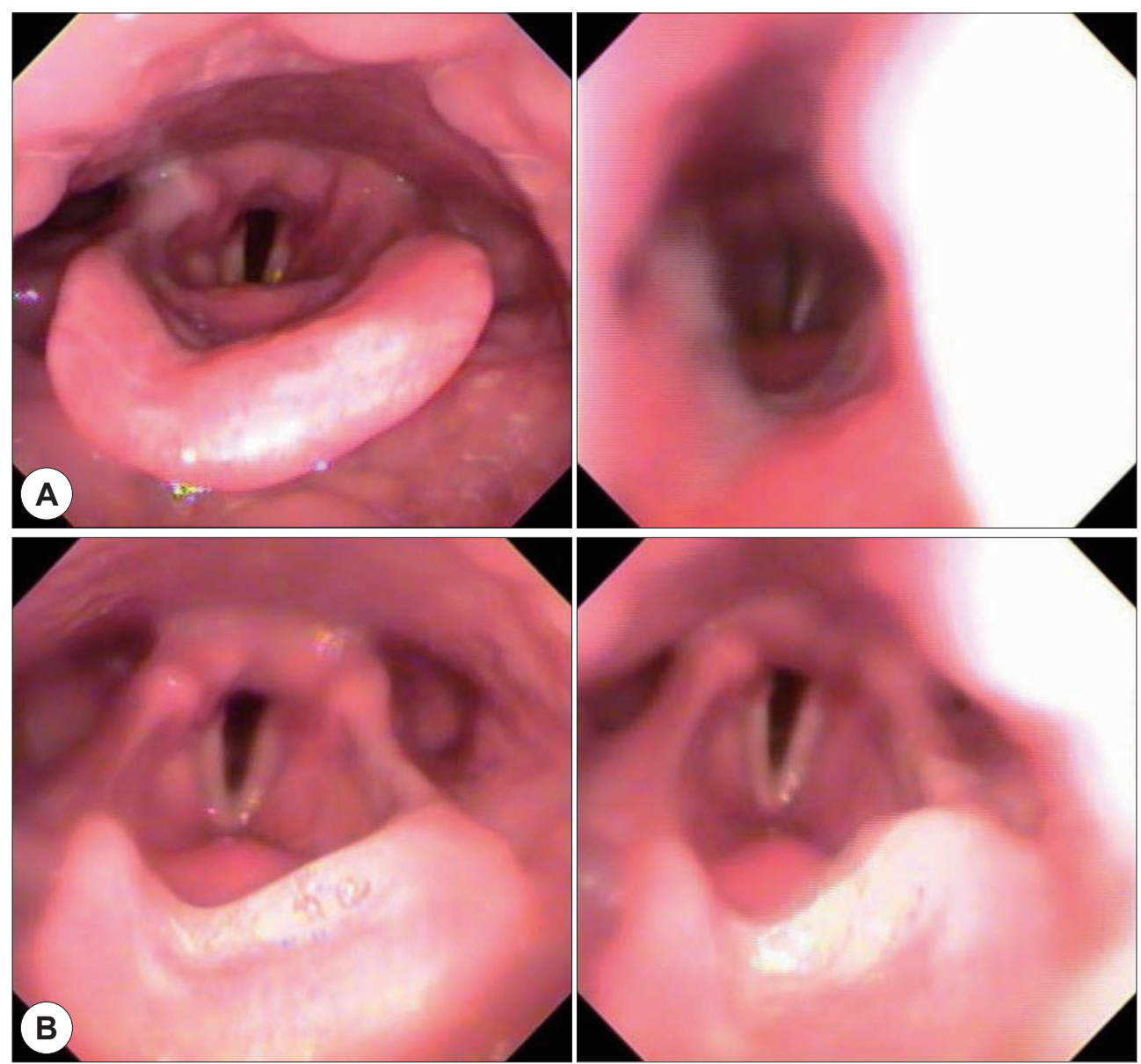

Fig. 1. A : Narrowing of the lateral diameter at the retrolingual level in a positional obstructive sleep apnea syndrome (OSAS) patient before introducing the modified jaw thrust maneuver during drug-induced sleep endoscopy (DISE). Expiration (Left). Inspiration (Right). B : Improvement of narrowing of the lateral diameter at the retrolingual level in a positional OSAS patient after introducing the modified jaw thrust maneuver during DISE. Expiration (Left). Inspiration (Right). 
in diameter was inserted softly through the nose and the pattern of upper airway obstruction was recorded. The modified jaw thrust maneuver was then performed and changes in the upper airway obstruction pattern were also recorded. After all, video images of all DISE procedures were evaluated by a single otolaryngologist. ${ }^{9)}$

\section{Classification of DISE findings}

We divided the upper airway into two parts : the retropalatal level (the region posterior to the soft palate) and the retrolingual level (the region of the pharynx posterior to the vertical portion of the tongue). The retropalatal level was subdivided into the palate [anteroposterior (AP) diameter] and lateral pharyngeal wall (lateral diameter). The retrolingual level was subdivided into the tongue base (AP diameter) and the lateral pharyngeal wall (lateral diameter). In addition, the stage of airway obstruction was classified as no obstruction (grade 0), partial obstruction (grade 1; 50-75\% obstruction), and complete obstruction (grade $2,>75 \%$ obstruction). ${ }^{10)}$ Thus, the patterns of upper airway obstruction in OSAS patients were evaluated and documented.

\section{Modified jaw thrust maneuver}

We introduced a modified jaw thrust maneuver during DISE, and airway structural changes induced by the modified jaw thrust maneuver were evaluated and documented. The degree of improvement in the pattern of airway obstruction was examined and the percentage of patients with changes in grade was calculated (Figs. 1, 2).

\section{Statistical analysis}

The Mann-Whitney U test and Fisher's exact test were used to compare the clinical characteristics and effects of the modified jaw thrust maneuver between positional OSAS and non-positional OSAS patients. All statistical tests were performed using IBM SPSS
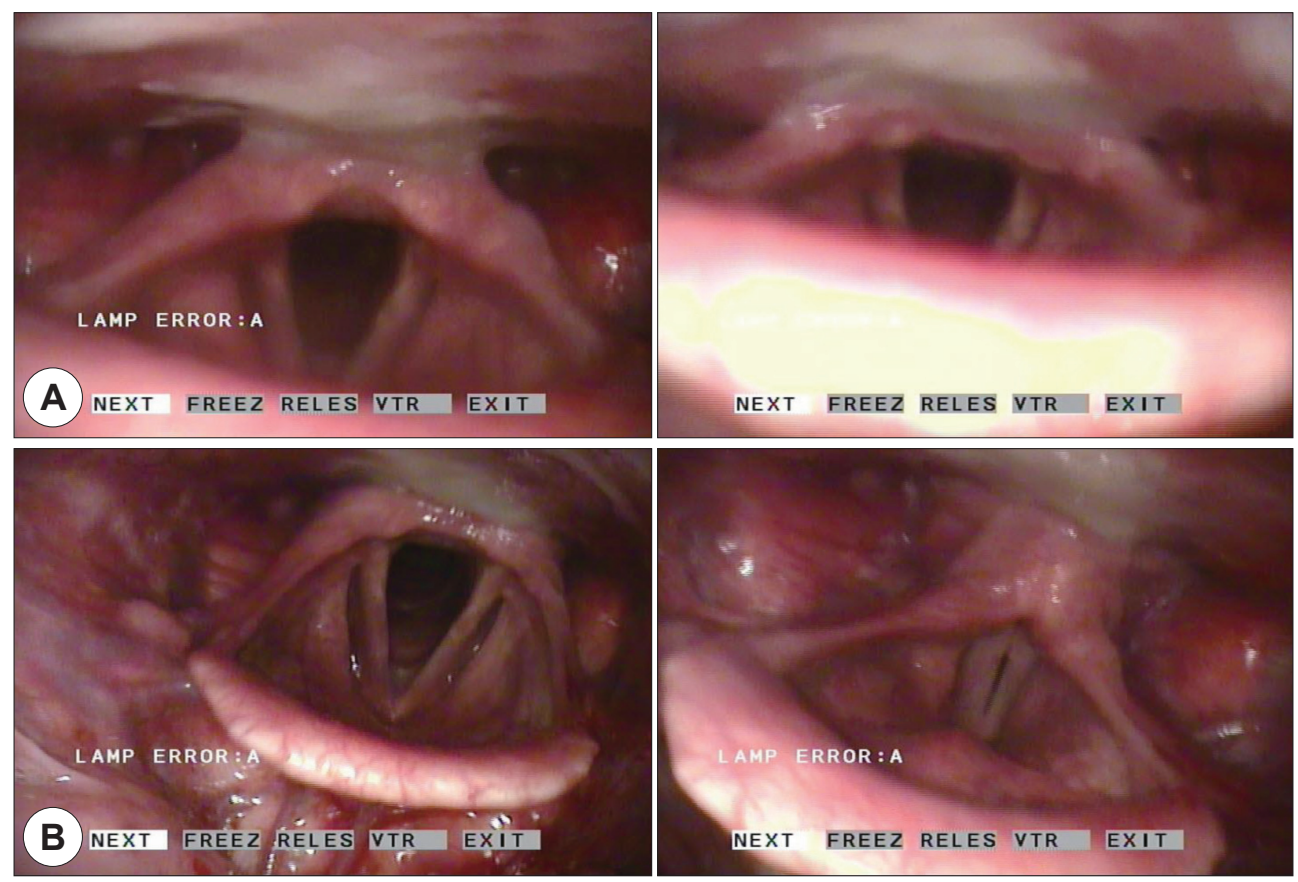

Fig. 2. A : Narrowing of the AP diameter at the retrolingual level in a non-positional OSAS patient before introducing the modified jaw thrust maneuver during DISE. Expiration (Left). Inspiration (Right). B : Improvement of narrowing of the AP diameter at the retrolingual level in a non-positional OSAS patient after introducing the modified jaw thrust maneuver during DISE. Expiration (Left). Inspiration (Right). 
Statistics software (ver. 23.0 ; IBM Corp., Chicago, IL). In all analyses, $\mathrm{p}<0.05$ was taken to indicate statistical significance.

\section{Results}

\section{Comparison of Friedman stage and tonsil grade between the two groups}

There were no statistically significant differences in Friedman stage or tonsil grade between the positional OSAS group and non-positional OSAS group ( $\mathrm{p}=0.586$ and 0.382 , respectively) (Table 2 ).

\section{Comparison of polysomnographic data between the two groups}

The mean arterial oxygen saturation $\left(\mathrm{SaO}_{2}\right)$, lowest $\mathrm{SaO}_{2}$, and total arousal index values were more se- vere in the non-positional OSAS patients, and the difference in total arousal index was statistically significant $(\mathrm{p}=0.027)$. The rapid eye movement (REM) sleep value was significantly lower in the non-positional OSAS patients than in the positional OSAS patients $(p=0.030)$. The remaining variables (AHI, sleep efficiency, NREM1 sleep, NREM2 sleep, and NREM3 sleep) were not significantly different between the two groups (Table 3).

\section{Comparison of DISE findings between the two groups}

There were no statistically significant differences in the pattern or degree of obstruction between the positional OSAS group and non-positional OSAS group (Table 4).

Table 2. Comparison of friedman stage and tonsil grade between the two groups

\begin{tabular}{lccc}
\hline & Positional & Non-positional & p-value \\
\hline Friedman stage & & & 0.586 \\
Low grade* $^{(\%)}$ & 35.3 & 42.1 & \\
High grade $^{\dagger}(\%)$ & 64.7 & 57.9 & 0.382 \\
Tonsil grade & & & \\
Low grade $^{\dagger}(\%)$ & 22.1 & 31.6 & 68.4 \\
High grade $^{\S}(\%)$ & 77.9 & & \\
\hline
\end{tabular}

Statistics, Fisher's exact test ; Statistical significance, $\mathrm{p}<0.05 . *$ : Low grade of Friedman stage : includes grade 1 and 2 of Friedman stage, $\dagger$ : High grade of Friedman stage : includes grade 3 and 4 of Friedman stage, $\neq:$ Low grade of tonsil grade: includes grade 0 and 1 of tonsil grade, $\S$ : High grade of tonsil grade : includes grade 2, 3 , and 4 of tonsil grade

Table 3. Comparison of polysomnographic data between the two groups

\begin{tabular}{lccc}
\hline & Positional & Non-positional & p-value \\
\hline AHI (mean \pm SD, events/h) & $24.6 \pm 13.8$ & $40.1 \pm 32.2$ & 0.267 \\
Mean SaO $_{2}$ (mean \pm SD, \%) & $96.7 \pm 1.7$ & $94.9 \pm 4.4$ & 0.429 \\
Lowest SaO $($ mean $\pm S D, \%)$ & $78.6 \pm 9.6$ & $69.9 \pm 17.3$ & 0.078 \\
Sleep Efficiency (mean $\pm S D, \%)$ & $82.8 \pm 9.7$ & $82.9 \pm 8.3$ & 0.677 \\
Total Arousal Index (mean \pm SD, events/h) & $26.6 \pm 11.9$ & $46.0 \pm 28.4$ & 0.027 \\
NREM1 Sleep (mean \pm SD, \%) & $39.9 \pm 15.2$ & $42.7 \pm 23.5$ & 0.715 \\
NREM2 Sleep (mean $\pm S D, \%)$ & $35.5 \pm 17.1$ & $36.8 \pm 19.9$ & 0.708 \\
NREM3 Sleep (mean $\pm S D, \%)$ & $2.5 \pm 3.8$ & $3.2 \pm 5.8$ & 0.846 \\
REM Sleep (mean $\pm S D, \%)$ & $21.4 \pm 9.2$ & $16.1 \pm 8.3$ & 0.030
\end{tabular}

Statistics, Mann-Whitney U-test ; Statistical significance, $\mathrm{p}<0.05$. AHI : apnea-hypopnea index, SD : standard deviation, SaO2 : oxygen saturation, REM : rapid eye movement, NREM1 : non-REM stage 1, NREM2 : non-REM stage 2 , NREM3 : non-REM stage 3 
Table 4. Comparison of DISE findings between the two groups

\begin{tabular}{|c|c|c|c|c|}
\hline & & Positional & Non-positional & p-value \\
\hline \multicolumn{5}{|c|}{ Retropalatal } \\
\hline \multirow[t]{2}{*}{ AP } & Low grade* (\%) & 5.9 & 10.5 & \multirow{2}{*}{0.608} \\
\hline & High grade $^{\dagger}(\%)$ & 94.1 & 89.5 & \\
\hline \multirow[t]{2}{*}{ Lateral } & Low grade* (\%) & 17.6 & 21.1 & \multirow{2}{*}{0.743} \\
\hline & High grade $^{\dagger}(\%)$ & 82.4 & 78.9 & \\
\hline \multicolumn{5}{|c|}{ Retrolingual } \\
\hline \multirow[t]{2}{*}{ AP } & Low grade* (\%) & 35.3 & 36.8 & \multirow{2}{*}{0.901} \\
\hline & High grade $^{\dagger}(\%)$ & 64.7 & 63.2 & \\
\hline \multirow[t]{2}{*}{ Lateral } & Low grade* (\%) & 25.0 & 26.3 & \multirow{2}{*}{1.000} \\
\hline & High grade $^{\dagger}(\%)$ & 75.0 & 73.7 & \\
\hline
\end{tabular}

Statistics, Fisher's exact test ; Statistical significance, $\mathrm{p}<0.05 . *$ : Low grade : includes grade $0, \dagger:$ High grade : includes grade 1 and 2. Retropalatal : region posterior to the soft palate, Retrolingual : region of the pharynx posterior to the vertical portion of the tongue, AP : anteroposterior

Table 5. Comparison of changes in DISE findings by modified jaw thrust maneuver between the two groups

\begin{tabular}{lccc}
\hline & Positional & Non-positional & p-value \\
\hline Retropalatal & & & \\
AP (\%) & 50.0 & 52.6 & 0.839 \\
$\quad$ Lateral (\%) & 35.3 & 36.8 & 0.901 \\
Retrolingual & & & \\
AP (\%) & 79.4 & 68.4 & 0.360 \\
Lateral (\%) & 73.5 & 52.6 & 0.082 \\
\hline
\end{tabular}

Statistics, Fisher's exact test; Statistical significance, $\mathrm{p}<$ 0.05 . Retropalatal : region posterior to the soft palate, Retrolingual : region of the pharynx posterior to the vertical portion of the tongue, AP : anteroposterior

\section{Comparison of changes in DISE findings by modi-} fied jaw thrust maneuver between the two groups

Retrolingual level obstruction showed a higher rate of airway opening in positional OSAS patients than in non-positional OSAS patients (79.4\% vs. $68.4 \%$ in AP and $73.5 \%$ vs. $52.6 \%$ in lateral, respectively), but the differences were not statistically significant $(\mathrm{p}=$ 0.360 in AP and $\mathrm{p}=0.082$ in lateral) (Table 5).

\section{Discussion}

Although the pathophysiology of OSAS is complicated, it is well known that sleep position affects the occurrence and severity of sleep apnea. ${ }^{4)}$ The underlying mechanism is thought to be related to gravity, but this remains to be confirmed. Several types of OSAS have been defined, with patients typically classified as having positional OSAS or non-positional OSAS. The most common definition of positional OSAS is total $\mathrm{AHI} \geq 5 / \mathrm{h}$ and supine $\mathrm{AHI}$ at least twice as high as non-AHI. ${ }^{1,11)}$ The frequency of positional OSAS among OSAS patients varies somewhat according to ethnicity, ranging from $67 \%$ to $75 \%$ in Asian populations $^{3,12)}$ and from $50 \%$ to $60 \%$ in Western populations. The high prevalence of OSAS in Asian populations is because Asian people have a lower BMI than Westerners, and obesity is an important determinant of positional OSAS. There have been a number of studies regarding anthropometric and PSG results according to OSAS subtype. Some groups reported that positional OSAS patients were younger and less obese, ${ }^{2,3)}$ while others found no differences in BMI between patients with positional and non-positional OSAS. ${ }^{13)}$ Oksenberg et al..$^{3)}$ reported that non-positional OSAS patients had significantly higher AI and AHI values, lower mean oxygen saturation, and longer snoring times than those with positional OSAS. These results were similar to those of other studies, as well as the present study.

MAD is a common non-surgical treatment for OSAS and is used as an alternative to positive airway pressure (PAP) devices. ${ }^{14,15}$ MAD maintains the mandib- 
ular position in the upper extremity, which enhances and collapses airway opening. MAD is currently the first-line treatment for mild OSA and severe OSA only when persistent PAP therapy fails or is rejected. ${ }^{16)} \mathrm{Al}$ though MAD significantly reduces OSAS in the majority of patients, about a third show negligible improvement. ${ }^{17)}$ Therefore, accurate prediction of treatment outcome is highly desirable. Understanding the patient's phenotype with regard to response to MAD therapy can improve patient selection.

In treatment planning for OSAS patients, it is important to identify the pattern and degree of airway obstruction. Diagnostic tools, such as computed tomography (CT) and magnetic resonance imaging (MRI), are widely used for anatomical evaluation of the upper airway. However, these tools are performed when the patient is awake and therefore do not accurately reflect the pattern of upper airway obstruction during sleep. On the other hand, DISE, designed by Croft and Pringle ${ }^{18)}$ in 1991, can be used to observe the site of upper airway occlusion during sleep. DISE uses sedative-hypnotics to induce obstruction in OSAS patients, thereby facilitating anatomical assessment of obstructive physiology. DISE has some limitations, but approaches a more actual sleep state better than other diagnostic tools. ${ }^{19)}$

The modified jaw thrust maneuver is an airway opening maneuver used during resuscitative efforts when there is suspicion of cervical injury. The modified jaw thrust maneuver performed during DISE is effective for clearing the airway and allows assessment of the degree of airway extension in OSAS patients. ${ }^{7}$ The modified jaw thrust maneuver and MAD are similar, in that the jaws are pulled forward against gravity. Therefore, the effect of MAD can be estimated by carrying out the modified jaw thrust maneuver during DISE. ${ }^{7)}$

This is the first study to compare the results of induced modified jaw thrust maneuver during DISE between positional OSAS patients and non-positional OSAS patients. Here, we compared the clinical characteristics of positional OSAS patients and non-posi- tional OSAS patients, and the findings of DISE and effects of the modified jaw thrust maneuver. 1) There were no statistically significant differences in Friedman stage or tonsil grade, BMI, ESS score, BP, AHI, or pattern of airway obstruction between the positional and non-positional OSAS patients. However, the mean $\mathrm{SaO}_{2}$, lowest $\mathrm{SaO}_{2}$, and total arousal index values were more severe in the non-positional OSAS patients. 2) After introducing the modified jaw thrust maneuver, retrolingual level obstruction tended to show a higher rate of airway opening in positional OSAS patients than in non-positional OSAS patients. This tendency may be clinically important for MAD, but further studies are required to examine this in more detail.

This study had some limitations. First, an insufficient number of cases have not yet been studied, and second there have been no studies to determine the effectiveness of treatment after wearing a MAD. Therefore, further research is required to address these issues.

The authors would like to thank Bo Hee Lee of the Institute of Statistical Research, Pusan National University.

\section{REFERENCES}

1) Norton PG, Dunn EV. Snoring as a risk factor for disease: an epidemiological survey. Br Med J 1985;291:630-2.

2) Cartwright RD. Effect of sleep position on sleep apnea severity. Sleep 1984;7:110-4.

3) Oksenberg A, Silverberg DS, Arons E, Radwan H. Positional vs nonpositional obstructive sleep apnea patients: anthropomorphic, nocturnal polysomnographic, and multiple sleep latency test data. Chest 1997;112:629-39.

4) Joosten SA, Hamza K, Sands S, Turton A, Berger P, Hamilton G. Phenotypes of patients with mild to moderate obstructive sleep apnoea as confirmed by cluster analysis. Respirology 2012;17:99-107.

5) Cartwright RD, Lloyd S, Lilie J, Kravitz H. Sleep position training as treatment for sleep apnea syndrome: a preliminary study. Sleep 1985;8:87-94.

6) Yoshida K. Influence of sleep posture on response to oral appliance therapy for sleep apnea syndrome. Sleep 2001;24: 538-44.

7) Uzun L, Ugur MB, Altunkaya H. Ozer Y, Ozkocak I, Demirel CB. Effectiveness of the jaw-thrust maneuver in opening the airway: a flexible fiberoptic endoscopic study. ORL J 
Otorhinolaryngol Relat Spec 2005;67:39-44.

8) Hernández-Gancedo C, Pestaña D, Peña N, Royo C, PérezChrzanowska H, Criado A. Monitoring sedation in critically ill patients: bispectral index, Ramsay and observer scales. Eur J Anaesthesiol 2006;23:649-53.

9) Koo SK, Ahn GY, Choi JW, Kim YJ, Jung SH, Moon JS, et al. Obstructive sleep apnea in postmenopausal women: a comparative study using drug induced sleep endoscopy. Braz J Otorhinolaryngol 2017;83:285-91.

10) Koo SK, Choi JW, Myung NS, Lee HJ, Kim YJ, Kim YJ. Analysis of obstruction site in obstructive sleep apnea syndrome patients by drug induced sleep endoscopy. Am J Otolaryngol 2013;34:626-30.

11) Block AJ, Boysen PG, Wynne JW, Hunt LA. Sleep apnea, hypopnea and oxygen desaturation in normal subjects: a strong male predominance. N Engl J Med 1979;300:513-7.

12) Richard W, Kox D, den Herder C, Laman M, van Tinteren $\mathrm{H}$, de Vries N. The role of sleeping position in obstructive sleep apnea. Eur Arch Otorhinolaryngol 2006;263:946-50.

13) Pevernagie DA, Shepard JW Jr. Relations between sleep stage, posture and effective nasal CPAP levels in OSA. Sleep 1992;15:162-7.

14) Clark GT, Blumenfeld I, Yoffe N, Peled E, Lavie P. A cross- over study comparing the efficacy of continuous positive airway pressure with anterior mandibular positioning devices on patients with obstructive sleep apnea. Chest 1996; 109:1477-83.

15) Clark GT, Sohn JW, Hong CN. Treating obstructive sleep apnea and snoring: assessment of an anterior mandibular positioning device. J Am Dent Assoc 2000;131:765-71.

16) Kushida CA, Littner MR, Morgenthaler T, Alessi CA, Bailey D, Coleman J Jr, et al. Practice parameters for the indications for polysomnography and related procedures: an update for 2005. Sleep 2005;28:499-521.

17) Sutherland K, Vanderveken OM, Tsuda H, Marklund M, Gagnadoux F, Kushida CA et al. Oral appliance treatment for obstructive sleep apnea: an update. J Clin Sleep Med 2014;10:215-27.

18) Croft CB, Pringle M. Sleep nasendoscopy: a technique of assessment in snoring and obstructive sleep apnea. Clin Otolaryngol Allied Sci 1991;16:504-9.

19) Koo SK, Kwon SB, Moon JS, Lee SH, Lee HB, Lee SJ. Comparison of snoring sounds between natural and druginduced sleep recorded using a smartphone. Auris Nasus Larynx 2018;45:777-82. 